\title{
Stress Intensity Solutions for Cracked Plates by the Dual Boundary Method
}

\author{
A. Sahli, D. Boutchicha, A. Belarbi, and O. Rahmani \\ Département de Génie Mécanique (USTO), Oran, Algérie
}

удК 539.4

\section{Расчет напряженно-деформированного состояния пластин с трещинами методом двойных граничных элементов}

\author{
А. Сахли, Д. Бучича, А. Беларби, О. Рахмани \\ Отделение технической механики, Оран, Алжир
}

Описано применение метода двойных граничных элементов для определения коэффиииентов интенсивности напряжений в задачах, связанных с изгибом пластин. Исследуемые условия нагружения включают внутреннее давление и комбинацио изгиба с растяжениел. Коэффищиенты интенсивности напряжений для смешанных мод оцениваются с помощью метода экстраполяции перемещения поверхности трещины и метода J-интеграла. Результатьи расчетов методом граничных элементов, полученные для рассматриваемых спучаев нагружения, сравниваются с данныли аналитических или конечноэлементных расчетов. Получено ux хорошее соответствие.

Ключевые слова: коэффициент интенсивности напряжений, метод граничных элементов, изгиб пластин, $J$-интеграл.

Introduction. Stress intensity factor solutions for several simple plate geometries loaded by tension and bending are available in a parametric form [1, 2]. However, for more general cases involving more complex geometry, numerical methods such as the boundary element method (BEM) or the finite element method (FEM) must be used for evaluation of fracture mechanics parameters. Therefore, there have been considerable developments in the use of the BEM for fracture analysis and there are many examples of its use for linear elastic fracture mechanics (LEFM) [3,4]. An alternative approach is to use the dual boundary element method (DBEM) with a single region being used in the analysis and one crack face being modeled using the displacement boundary integral equation and the other crack face being modeled using the traction boundary integral equations. The DBEM therefore requires no subregioning and eliminates the singular algebraic equations.

The purpose of the present paper is to illustrate the effectiveness of the DBEM for the LEFM analysis of plate bending problems. The DBEM is used to analyze several crack configurations in plates, including center crack, edge crack and cracks emanating from a hole in a finite width plate loaded by either bending and tension or uniform pressure, and the $K_{\mathrm{I}}, K_{\mathrm{II}}$, and $K_{\mathrm{III}}$ stress intensity factors are presented. The results for the case studies discussed in this paper have 
been compared with either analytical or finite element results and in all cases the boundary element results are in good agreement with the results from alternative sources.

1. Plate Bending Equations. Reissner's [5, 6] plate bending equations are used to obtain the fundamental solutions for the boundary integral equations:

$$
\Delta_{i j}^{*} u_{j}+b_{i}=0
$$

where $\Delta_{i j}^{*}$ is the Navier operator and can be expressed as

$$
\begin{gathered}
\Delta_{\alpha \beta}^{*}=\frac{D(1-v)}{2}\left[\left(\nabla^{2}-\lambda^{2}\right) \delta_{\alpha \beta}+\frac{(1+v)}{(1-v)} \frac{\partial^{2}}{\partial x_{\alpha} \partial x_{\beta}}\right], \\
\Delta_{\alpha 3}^{*}=-\Delta_{\alpha 3}^{*}=-\frac{D(1-v)}{2} \lambda^{2} \frac{\partial}{\partial x_{\alpha}}, \\
\Delta_{33}^{*}=-\frac{D(1-v)}{2} \lambda^{2} \Delta^{2},
\end{gathered}
$$

where $\nabla^{2}$ is the Laplace operator and $b_{i}$ represents the loading on the plate,

$$
\begin{gathered}
b_{\alpha}=\frac{v q_{, \alpha}}{\lambda^{2}(1-v)}, \\
b_{3}=q .
\end{gathered}
$$

In Eqs. (1), (2a)-(2e), $v$ is Poisson's ratio, $q$ is the distributed load on the plate surface, $\delta_{\alpha \beta}$ is the Dirac delta function, and $D$ and $\lambda$ are given by the following equations:

$$
\begin{gathered}
D=\frac{E h^{3}}{12\left(1-v^{2}\right)}, \\
\lambda=\frac{\sqrt{10}}{h},
\end{gathered}
$$

in which $E$ is Young's module and $h$ is the plate thickness.

2. The Dual Boundary Integral Equations. The dual equations, on which the dual boundary element method is based, are the displacement and the traction boundary integral equations. The displacement boundary integral equations for Reissner plate model were reported in [7]. The traction integral equations for Reissner plates have been reported independently in [8] and [9]. In this paper, these boundary integral equations are used. The boundary integral representation 
of the displacement components $w_{i}$ can be written for an internal source point $X^{\prime}$ as

$$
\begin{aligned}
& w_{i}\left(X^{\prime}\right)+\int_{\Gamma} P_{l j}^{*}\left(X^{\prime}, x\right) w_{j}(x) d \Gamma(x)=\int_{\Gamma} W_{i j}^{*}\left(X^{\prime}, x\right) p_{j}(x) d \Gamma(x)+ \\
& \quad+\int_{\Omega}\left(W_{i 3}^{*}\left(X^{\prime}, X\right)-\frac{v}{(1-v) \lambda^{2}} W_{i \alpha, \alpha}^{*}\left(X^{\prime}, X\right)\right) q_{3}(X) d \Omega(X),
\end{aligned}
$$

where $w_{\alpha}$ are rotations of $x$ - and $y$-axes, respectively, $w_{3}$ is out of plane displacement, $p_{j}$ are bending moment and shear tractions, respectively, and $q_{3}$ is internal pressure. Roman indices vary from 1 to 3 and Greek indices vary from 1 to 2 . The values $P_{i j}^{*}\left(X^{\prime}, x\right)$ and $W_{i j}^{*}\left(X^{\prime}, x\right)$ represent the Reissner plate fundamental solutions at the boundary point $x$.

The above integrals are regular provided $r \neq 0$. If the point $X^{\prime}$ is placed at the boundary, that is $X^{\prime} \rightarrow x^{\prime} \in \Gamma$, the distance $r$ tends to zero and, in the limit, the fundamental solutions exhibit singularities. Assuming that the displacements $w_{j}$ satisfy the Hölder continuity, Eq. (4) for the source points on the boundary can be written as follows:

$$
\begin{gathered}
c_{i j}\left(x^{\prime}\right) w_{j}\left(x^{\prime}\right)+\int_{\Gamma} P_{i j}^{*}\left(x^{\prime}, x\right) w_{j}(x) d \Gamma(x)=\int_{\Gamma} W_{i j}^{*}\left(x^{\prime}, x\right) p_{j}(x) d \Gamma(x)+ \\
+\int_{\Omega}\left(W_{i 3}^{*}\left(x^{\prime}, X\right)-\frac{v}{(1-v) \lambda^{2}} W_{i \alpha, \alpha}^{*}\left(x^{\prime}, X\right)\right) q_{3}(X) d \Omega(X),
\end{gathered}
$$

where the integral in the left hand side denotes a Cauchy principal value integral, $x^{\prime}, x \in \Gamma$ are source and field points, respectively, and $c_{i j}\left(x^{\prime}\right)$ are the jump terms. The term $c_{i j}\left(x^{\prime}\right)$ is equal to $\frac{1}{2} \delta_{i j}$ when $x^{\prime}$ is located on a smooth boundary.

By applying the divergence theorem, the last domain integral in (5) can be transferred to boundary integral, in the case of a uniform load $\left(q_{3}=\right.$ const $)$ to give:

$$
\begin{aligned}
& \int_{\Omega}\left(W_{i 3}^{*}\left(x^{\prime}, X\right)-\frac{v}{(1-v) \lambda^{2}} W_{i \alpha, \alpha}^{*}\left(x^{\prime}, X\right)\right) q_{3}(X) d \Omega(X)= \\
& =q_{3} \int_{\Gamma}\left(V_{i, \alpha}^{*}\left(x^{\prime}, x\right)-\frac{v}{(1-v) \lambda^{2}} W_{i \alpha}^{*}\left(x^{\prime}, x\right)\right) n_{\alpha}(x) d \Gamma(x),
\end{aligned}
$$

where $V_{i, \alpha}^{*}$ are the particular solutions of the equation $V_{i, \theta \theta}^{*}=W_{i 3}^{*}$.

The stress resultant components are obtained by differentiation of equation (4) with respect to the coordinate of the source point $X^{\prime}$ and then substituting them into the stress displacement relations for Reissner plate theory to give: 


$$
\begin{aligned}
M_{\alpha, \beta}\left(X^{\prime}\right) & =\int_{\Gamma} W_{\alpha \beta k}^{*}\left(X^{\prime}, x\right) p_{k}(x) d \Gamma(x)-\int_{\Gamma} P_{\alpha \beta k}^{*}\left(X^{\prime}, x\right) w_{k}(x) d \Gamma(x)+ \\
& +q \int_{\Gamma} Q_{\alpha \beta}^{*}\left(X^{\prime}, x\right) d \Gamma(x)+\frac{v}{(1-v) \lambda^{2}} q \delta_{\alpha \beta}, \\
Q_{\beta}\left(X^{\prime}\right) & =\int_{\Gamma} W_{3 \beta k}^{*}\left(X^{\prime}, x\right) p_{k}(x) d \Gamma(x)-\int_{\Gamma} P_{3 \beta k}^{*}\left(X^{\prime}, x\right) w_{k}(x) d \Gamma(x)+ \\
& +q \int_{\Gamma} Q_{\alpha \beta}^{*}\left(X^{\prime}, x\right) d \Gamma(x),
\end{aligned}
$$

where $M_{\alpha, \beta}$ and $Q_{\beta}$ are bending moment and shear force stress resultants, respectively.

The kernels $W_{i j k}^{*}, P_{i j k}^{*}$ are obtained from linear combination of derivatives of $W_{i j}^{*}$ and $P_{i j}^{*}$, respectively, and $Q_{i \beta}$ - from linear combination of derivatives of $W_{i 3}^{*}$ and $W_{i \theta, \theta}^{*}$.

By moving the source point $X^{\prime}$ to the boundary and multiplying all the terms by the unit outward normal $n_{\beta}$ to the boundary at the source point $x^{\prime}$, the traction integral equations are obtained as follows:

$$
\begin{gathered}
\frac{1}{2} p_{\alpha}(x)+n_{\beta}\left(x^{\prime}\right) \int_{\Gamma} P_{\alpha \beta \gamma}^{*}\left(x^{\prime}, x\right) w_{\gamma}(x) d \Gamma(x)+n_{\beta}\left(x^{\prime}\right) \int_{\Gamma}\left(x^{\prime}, x\right) w_{3}(x) d \Gamma(x)= \\
=n_{\beta}\left(x^{\prime}\right) \int_{\Gamma} W_{\alpha \beta \gamma}^{*}\left(x^{\prime}, x\right) p_{\gamma}(x) d \Gamma(x)+n_{\beta}\left(x^{\prime}\right) \int_{\Gamma} W_{\alpha \beta \gamma}^{*}\left(x^{\prime}, x\right) p_{3}(x) d \Gamma(x)+ \\
+q n_{\beta}\left(x^{\prime}\right) \int_{\Gamma} Q_{\alpha \beta}^{*}\left(x^{\prime}, x\right) d \Gamma(x)+\frac{1}{2} \frac{q v}{(1-v) \lambda^{2}} n_{\alpha}\left(x^{\prime}\right) \\
\frac{1}{2} p_{3}(x)+n_{\beta}\left(x^{\prime}\right) \int_{\Gamma} P_{3 \beta \gamma}^{*}\left(x^{\prime}, x\right) w_{\gamma}(x) d \Gamma(x)+n_{\beta}\left(x^{\prime}\right) \int_{\Gamma} P_{3 \beta 3}^{*}\left(x^{\prime}, x\right) w_{3}(x) d \Gamma(x)= \\
=n_{\beta}\left(x^{\prime}\right) \int_{\Gamma} W_{3 \beta \gamma}^{*}\left(x^{\prime}, x\right) p_{\gamma}(x) d \Gamma(x)+n_{\beta}\left(x^{\prime}\right) \int_{\Gamma} W_{3 \beta 3}^{*}\left(x^{\prime}, x\right) p_{3}(x) d \Gamma(x)+ \\
+q n_{\beta}\left(x^{\prime}\right) \int_{\Gamma} Q_{3 \beta}^{*}\left(x^{\prime}, x\right) d \Gamma(x)
\end{gathered}
$$

where $p_{\alpha}=M_{\alpha \beta} n_{\beta}$ and $p_{3}=Q_{\beta} n_{\beta}$. The second integral in the left hand side stands for the Hadamard principal value integral.

Equations (8)-(9) represent three traction integral equations, and together with the three displacement integral equations in Eq. (5) form the dual boundary integral formulation. 
3. Numerical Implementation. In order to implement the DBEM numerically, the boundary including crack surfaces are discretized into elements. The general modelling strategies used in this work are similar to those used in [10] and can be summarized as follows:

(i) crack boundaries are modelled with discontinuous quadratic elements, as shown in Fig. 1 to satisfy continuity conditions of displacements and its derivatives in all nodes for the existence of principal value integrals; in such a way that each node of one of the crack surfaces is coincident with the node on the opposite surface;

(ii) the traction equations (8) (9) are applied for collocation on one of the crack surfaces;

(iii) the displacement equation (5) are applied for collocation on the opposite crack surface and the other non-crack boundaries;

(iv) continuous quadratic elements are applied along the remaining boundary of the body, except at the intersection between a crack and an edge, where discontinuous or semidiscontinuous ones are required on the edge, in order to avoid a common node at intersection, and also at boundary corner, where semidiscontinuous elements are preferred, in order to avoid a common node at the corner.

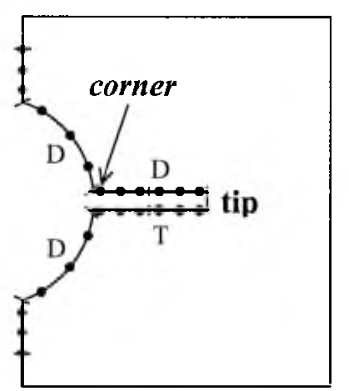

Fig. 1. Dual boundary element model $[(D)$ displacement equation; $(T)$ traction equation; $(\bullet)$ element node].

This simple strategy is robust and allows the DBEM to effectively model general edge or embedded crack problems; on the other hand, crack tips, crackedge corners and crack kinks require no special treatment, since they are not located at nodal points where the collocation is carried out.

4. Stress Intensity Factors Evaluation. The stress resultant intensity factors $K_{1}, K_{2}$, and $K_{3}$ are usually used instead of the stress intensity factors $K_{\mathrm{I}}, K_{\mathrm{II}}$, and $K_{\mathrm{III}}$. The relationship between the stress resultant intensity factors and the stress intensity factors are [11]:

$$
K_{\mathrm{I}}=\frac{12 z}{h^{3}} K_{1}, \quad K_{\mathrm{II}}=\frac{12 z}{h^{3}} K_{2}, \quad K_{\mathrm{III}}=\frac{3}{2 h}\left[1-\left(\frac{2 z}{h}\right)^{2}\right] K_{3} .
$$

The stress resultant intensity factors can be evaluated in several ways. In this work, the $J$-integral technique is employed to calculate the stress resultant intensity factors. The path independent $J$-integral is defined for plate bending as [12]: 


$$
J_{\delta b}=\int_{\Gamma}\left(W_{b}-q w_{3}\right) n_{\delta} d \Gamma-\int_{\Gamma} p_{i} w_{i, \delta} d \Gamma+\int_{\Omega} q_{, \delta} w_{3} d \Omega .
$$

The strain energy density for plate bending, $W_{b}$, is defined as

$$
W_{b}=\frac{1}{2}\left[M_{\alpha \beta}\left(\frac{w_{\alpha, \beta}+w_{\beta, \alpha}}{2}\right)+Q_{\alpha}\left(w_{\alpha}+w_{3, \alpha}\right)\right] \text {, }
$$

where $w_{i, j}$ is the strain tensor, and $n_{\alpha}$ are the components of the unit outward normal to the contour path.

To decouple the related stress intensity factors of a mixed mode problem from $J$-integral, an extension of a simple procedure which has been developed in [13] based on the decomposition of the elastic fields into symmetric and anti-symmetric mode component is used (Fig. 2). Using this procedure, only one component of $J$-integral is required.

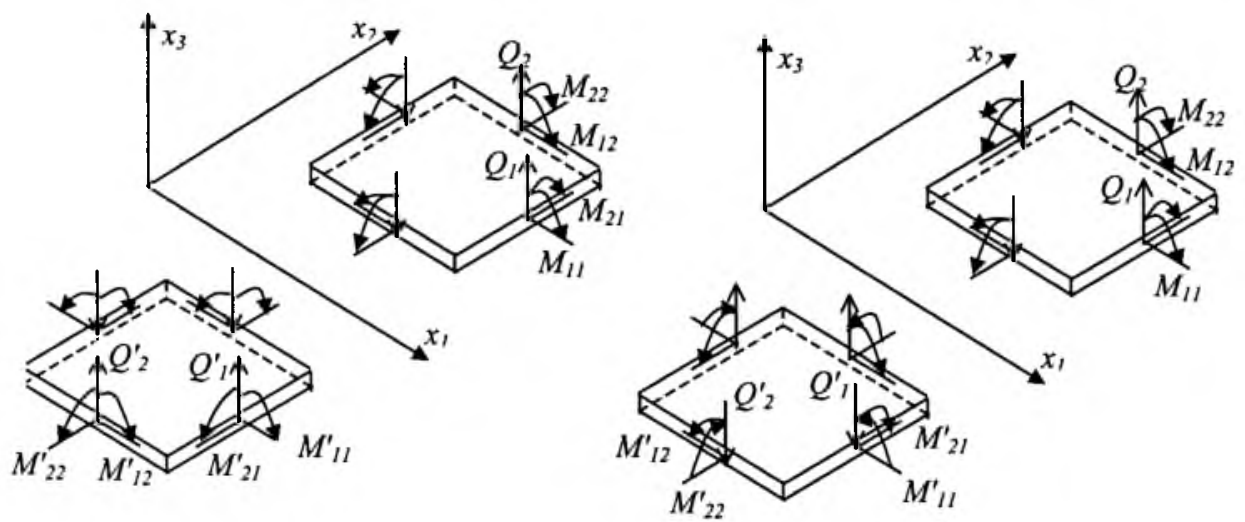

Fig. 2. Symmetric and anti-symmetric moment and shear force stress resultants at two points located symmetrically relative to the crack axis.

The relationship between the component of $J$-integral in $x_{1}$ direction and the stress resultant intensity factors for plate bending is given as

$$
J_{1 b}=\frac{12 \pi}{E h^{3}}\left[K_{1}^{2}+K_{2}^{2}+\frac{h^{2}}{10}(1+v) K_{3}^{2}\right] .
$$

The decomposition of the elastic fields are as follows:

$$
\left\{\begin{array}{l}
M_{11}^{S} \\
M_{12}^{S} \\
M_{22}^{S} \\
Q_{1}^{S} \\
Q_{2}^{S}
\end{array}\right\}=\frac{1}{2}\left\{\begin{array}{c}
M_{11}+M_{11}^{\prime} \\
M_{12}-M_{12}^{\prime} \\
M_{22}+M_{22}^{\prime} \\
Q_{1}+Q_{1}^{\prime} \\
Q_{2}-Q_{2}^{\prime}
\end{array}\right\}, \quad\left\{\begin{array}{c}
M_{11}^{A S} \\
M_{12}^{A S} \\
M_{22}^{A S} \\
Q_{1}^{A S} \\
Q_{2}^{A S}
\end{array}\right\}=\frac{1}{2}\left\{\begin{array}{c}
M_{11}-M_{11}^{\prime} \\
M_{12}+M_{12}^{\prime} \\
M_{22}-M_{22}^{\prime} \\
Q_{1}-Q_{1}^{\prime} \\
Q_{2}+Q_{2}^{\prime}
\end{array}\right\} .
$$


Applying the decomposition procedure, the integral $J_{1}$ can be represented by the sum of two integrals as follows:

$$
J_{1}=J_{1}^{S}+J_{1}^{A S},
$$

where the superscript indicates the pertinent deformation mode.

Finally, the stress intensity factors are obtained from the following relationship:

$$
J_{1 b}^{S}=J_{1 b}^{\mathrm{I}}=\frac{12 \pi K_{1}^{2}}{E h^{3}}, \quad J_{1 b}^{A S}=J_{1 b}^{\mathrm{II}}+J_{1 b}^{\mathrm{III}}=\frac{12 \pi}{E h^{3}}\left[K_{2}^{2}+\frac{h^{2}(1+v)}{10} K_{3}^{2}\right] .
$$

To split mode II and mode III components from $J_{1 b}^{A S}$, the displacement ratio as proposed in [14] are used

$$
\begin{gathered}
\Delta w_{1}=w_{1\left(+180^{\circ}\right)}-w_{1\left(-180^{\circ}\right)}=\frac{48}{E h^{3}} \sqrt{2 r} K_{2}, \\
\Delta w_{3}=w_{3\left(+180^{\circ}\right)}-w_{3\left(-180^{\circ}\right)}=\frac{24(1+v)}{5 E h} \sqrt{2 r} K_{3}, \\
\frac{\Delta w_{1}}{\Delta w_{3}}=\frac{10}{(1+v) h^{2}} \frac{K_{2}}{K_{3}} .
\end{gathered}
$$

Substituting Eq. (19) into Eq. (16) the following relations hold:

$$
\tilde{J}_{1 b}^{A S}=\frac{12 \pi(1+v)}{10} \widetilde{K}_{3}^{2}\left[\frac{h^{2}(1+v)}{10 E h}\left(\frac{\Delta w_{1}}{\Delta w_{3}}\right)^{2}+1\right]
$$

or

$$
J_{1 b}^{A S}=\frac{12 \pi(1+v)}{E h^{3}} K_{2}^{2}\left[1+\frac{10}{h^{2}(1+v)}\left(\frac{\Delta w_{3}}{\Delta w_{1}}\right)^{2}\right]
$$

To implement this procedure into the boundary element analysis, a circular contour path around the crack tip is defined as a set of internal points located at symmetrical positions relative to the crack plane, as shown in Fig. 3. The numerical integration along the contour path is accomplished using the trapezoidal rule.

\section{Case Studies.}

5.1. Square Plate with a Central Crack and Edge Twisting Moments (Fig. 4). An infinite plate subjected to twisting moments, as shown in Fig. 4, is considered in this case study. Because of the symmetrical nature of the loading and geometry, only half of the plate was analyzed, with the line of symmetry being perpendicular to the crack. The boundary conditions on the line of symmetry were assumed to be $x_{1}=0, \phi_{2}=M_{11}=w=0$. 


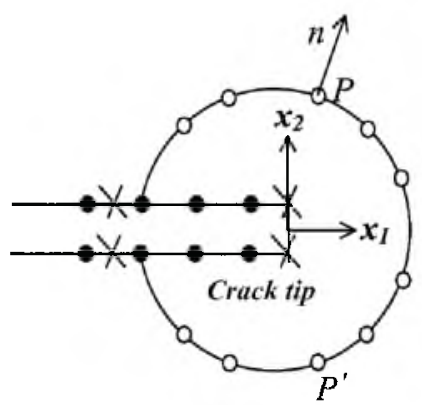

Fig. 3. Local crack tip coordinate reference system and contour path for the $J$-integral.

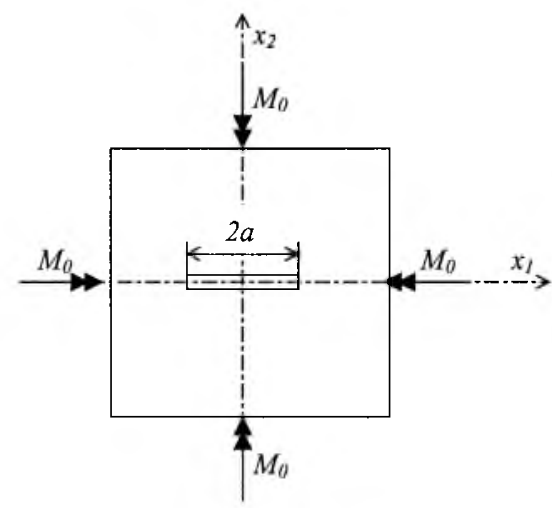

Fig. 4. Plate with edge twisting moments

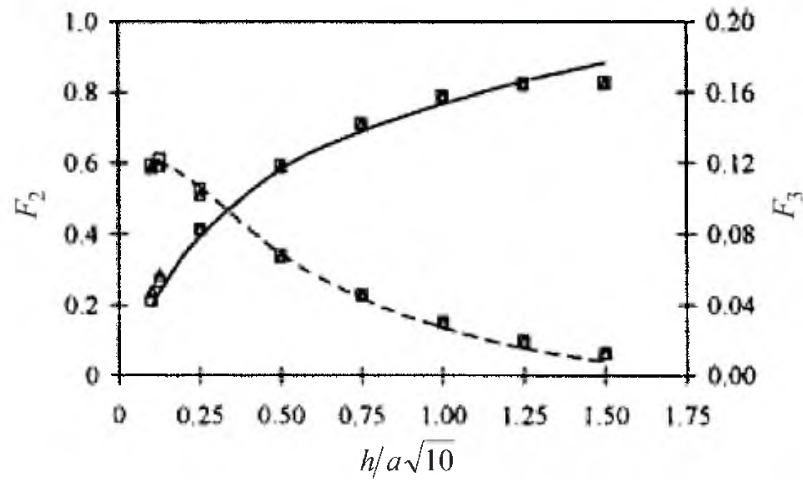

Fig. 5. Normalized intensity factors for plate with edge twisting [lines correspond [11]; $\triangle$ ) quarter point; $(\square) J$-integral]

In this case study Young's modulus was assumed to be $2 \cdot 10^{5} \mathrm{MPa}$ with Poisson's ratio being set to zero. Results are given in Fig. 5 for the quarter point and the $J$-integral methods for a range of crack lengths and one plate thickness for the normalized moment and shear force intensity factors $F_{2}$ and $F_{3}$, which are obtained from the following equations:

$$
F_{2}=\frac{K_{2}}{M_{0} \sqrt{a}}
$$




$$
F_{3}=\frac{(1+v) h K_{3}}{M_{0} \sqrt{10 \bar{a}}}
$$

The DBEM results are also compared in Fig. 5 with Sih's [2] analytical results. The $J$-integral results for $F_{2}$ and $F_{3}$ are also presented in Table 1.

T a b l e 1

Normalized Moment and Shear Force Intensity Factors for a Cracked Plate Subjected to Twisting Moment Calculated from $J$-Integral Paths

\begin{tabular}{|c|c|c|c|c|c|c|}
\hline$\frac{h}{a \sqrt{10}}$ & \multicolumn{3}{|c|}{$F_{2}$} & \multicolumn{3}{|c|}{$F_{3}$} \\
\hline 0.100 & Path 1 & Path 2 & Path 3 & Path 1 & Path 2 & Path 3 \\
\hline .125 & 0.2301 & 0.2207 & 0.2123 & 0.1242 & 0.1191 & 0.1146 \\
0.250 & 0.2794 & 0.2727 & 0.2663 & 0.1253 & 0.1223 & 0.1194 \\
0.500 & 0.4164 & 0.4141 & 0.4126 & 0.1056 & 0.1050 & 0.1046 \\
0.750 & 0.5961 & 0.5933 & 0.5932 & 0.0684 & 0.0681 & 0.0681 \\
1.000 & 0.7166 & 0.7132 & 0.7136 & 0.0457 & 0.0455 & 0.0455 \\
1.250 & 0.7942 & 0.7905 & 0.7911 & 0.0305 & 0.0303 & 0.0304 \\
1.500 & 0.8295 & 0.8254 & 0.8260 & 0.0198 & 0.0197 & 0.0197 \\
\hline
\end{tabular}

5.2. Cantilever Rectangular Plate with Edge Moment, Central Crack, and Central Hole (Fig. 6).

Results are given in Fig. 7 for this case study for a range of crack lengths and two plate thicknesses. The results for the $F_{1}$ normalized intensity factors have been obtained using the quarter point and the $J$-integral methods. The DBEM results have been verified using a 500-element FEM model. The $J$-integral results for this case study are also shown in Table 2.

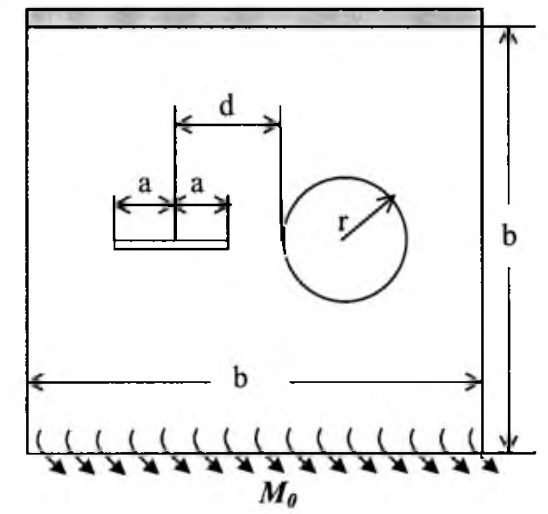

Fig. 6. Cantilever plate with internal crack and internal hole.

The normalized stress intensity factor, $F_{1}$, is related to the moment intensity factor $K_{1}$ by the expression

$$
F_{1}=\frac{K_{1}}{q b^{2} \sqrt{a}} .
$$


$\mathrm{T}$ a b 1 e 2

Normalized Moment Intensity factors for a Plate with a Central Crack and a Hole Subjected to Edge Moment Calculated from $J$-Integral Paths

\begin{tabular}{|c|c|c|c|c|c|c|}
\hline \multirow[t]{2}{*}{$\frac{a}{d}$} & \multicolumn{3}{|c|}{$\frac{h}{a \sqrt{10}}=1.0$} & \multicolumn{3}{|c|}{$\frac{h}{a \sqrt{10}}=0.1$} \\
\hline & Path 1 & Path 2 & Path 3 & Path 1 & Path 2 & Path 3 \\
\hline 0.1 & 1.1841 & 1.1852 & 1.1853 & 1.3265 & 1.3338 & 1.3372 \\
\hline 0.2 & 1.0965 & 1.0973 & 1.0974 & 1.3122 & 1.3146 & 1.3147 \\
\hline 0.3 & 1.0671 & 1.0672 & 1.0672 & 1.3219 & 1.3229 & 1.3245 \\
\hline 0.4 & 1.0658 & 1.0659 & 1.0658 & 1.3495 & 1.3493 & 1.3493 \\
\hline 0.5 & 1.0845 & 1.0844 & 1.0927 & 1.3926 & 1.3928 & 1.4028 \\
\hline 0.6 & 1.1230 & 1.1228 & 1.1313 & 1.4591 & 1.4591 & 1.4689 \\
\hline 0.7 & 1.1890 & 1.1977 & 1.0846 & 1.5623 & 1.5754 & 1.4050 \\
\hline 0.8 & 1.3088 & 1.3177 & 1.1981 & 1.7355 & 1.7482 & 1.5668 \\
\hline 0.9 & 1.5883 & 1.4657 & - & 2.1172 & 1.9153 & - \\
\hline
\end{tabular}

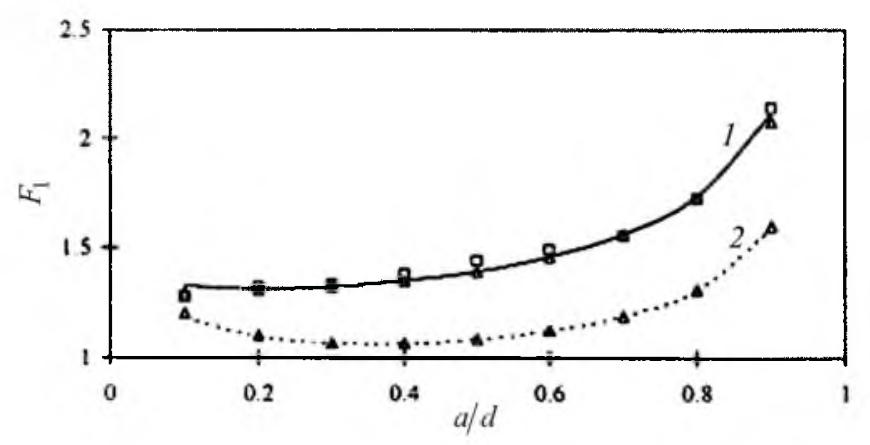

Fig. 7. Normalized intensity factors for a plate with internal crack and internal hole $[(\square)$ quarter point; $(\triangle)$ FEM; lines correspond $J$-integral: (l) $h / d \sqrt{10}=1.0 ;$ (2) $h / d \sqrt{10}=0.1$.

5.3. Rectangular T-Shaped Plate with Edge Moment and Edge Cracks (Fig. 8).

This case study comprises a cantilever T-shaped plate subjected to a uniformly distributed bending moment with perpendicular edge cracks at the junction of the $\mathrm{T}$ as shown in Fig. 8. DBEM quarter point, stress extrapolation and $J$-integral results for the $F_{1}$ normalized intensity factor for a range of crack lengths and a single plate thickness are presented in Fig. 9. The $J$-integral results for this case study are also given in Table 3.

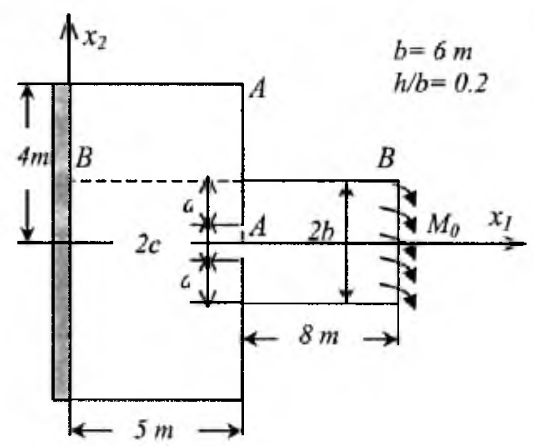

Fig. 8. T-shaped cantilever plate. 
Stress Intensity Solutions for Cracked Plates...

\begin{tabular}{|c|c|c|c|}
\hline \multicolumn{4}{|c|}{ Normalized Moment Int } \\
\hline \multirow{2}{*}{$\frac{a}{b}$} & \multicolumn{3}{|c|}{$F_{1}$} \\
\hline & Path 1 & Path 2 & Path 3 \\
\hline 0.1 & 0.2828 & 0.2862 & 0.2828 \\
\hline 0.2 & 0.3112 & 0.3114 & 0.3142 \\
\hline 0.3 & 0.3489 & 0.3481 & 0.3539 \\
\hline 0.4 & 0.3758 & 0.3753 & 0.3788 \\
\hline 0.5 & 0.3980 & 0.3978 & 0.4003 \\
\hline 0.6 & 0.4171 & 0.4168 & 0.4195 \\
\hline 0.7 & 0.4354 & 0.4349 & 0.4377 \\
\hline 0.8 & 0.4565 & 0.4561 & 0.4590 \\
\hline 0.9 & 0.4841 & 0.4837 & 0.4865 \\
\hline & & & 0.5393 \\
\hline
\end{tabular}

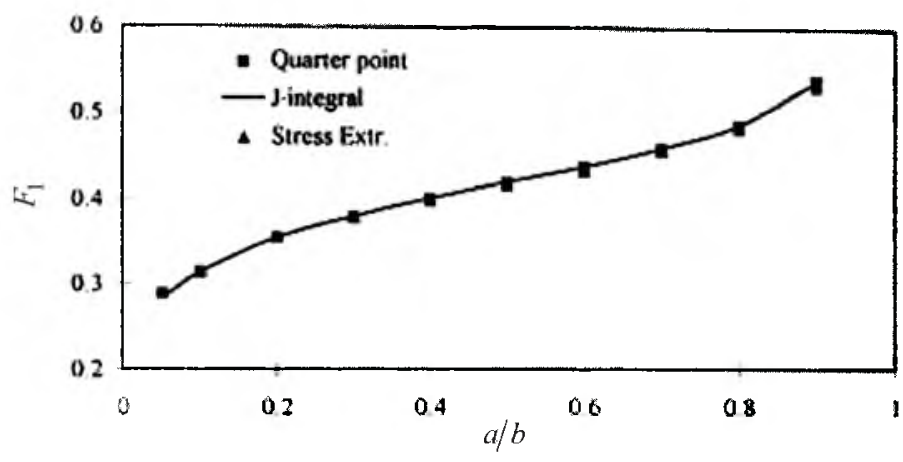

Fig. 9. Normalized intensity factors for a T-shaped cantilever plate.

6. Discussion of Results. Results are presented graphically in Figs. 5, 7, and 9 for the various normalized intensity factors for the case studies shown in Figs. 4 , 6 , and 8. Plates with a range of crack lengths, loading conditions, plan forms and boundary conditions were analyzed to investigate the effectiveness of the DDEM for the evaluation of the stress intensity factors in cracked plates. The displacement extrapolation, quarter point, stress extrapolation and $J$-integral methods have been used to calculate the moment and shear force intensity factors and in all cases the DBEM results are in close agreement with each other. Moreover, the DBEM results for the first case study (Fig. 4) are in good agreement with results obtained by Sih [2], who used the FEM in conjunction with the $J$-integral method to evaluate the stress intensity factors at the crack tip. However, for the third case study (Fig. 8), the FEM model with its 500 elements compares unfavourably with the DBEM model, which required only 40 boundary elements. Quarter point elements were used at the crack tip for the finite element study and the $J$-integral approach was used to evaluate the stress intensity factors at the crack tip. For this case study, the DBEM and the FEM results are in good agrcement. Tables 1-3 give details of the normalized intensity factors for the various case studies investigated. The results show a high degree of stability for each $J$-integral path for all crack lengths, plate thicknesses, loading conditions and boundary conditions. 
The values of the normalized crack tip intensity factors which are presented in this paper can be converted to bending moment, twisting moment, and shear force intensity factors, $K_{1}, K_{2}$, and $K_{3}$, from which Eq. (10) can be used to evaluate the stress intensity factors, $K_{\mathrm{I}}, K_{\mathrm{II}}$, and $K_{\mathrm{III}}$, at the crack tip.

Conclusions. The application of the DBEM for the LEFM analysis of plate bending problems is discussed. The method has been extended in this paper to enable the stress intensity factors in plate bending problems to be evaluated. In particular, the displacement ratio approach for the evaluation of $J$-integrals for three-dimensional fracture analysis has been developed further to deal with $J$-integrals arising in the fracture analysis of plate bending problems. Results for the normalized intensity factors for a number of case studies, including plates with cracks at boundary discontinuities are presented. The displacement, bending moments and twisting moments for the plates under consideration were evaluated using the DBEM. These DBEM results were then used in conjunction with the $J$-integral method to determine the normalized stress intensity factors at the crack tips. The crack tip stress intensity factors can then be evaluated from the normalized intensity factors. The BEM results were compared with either analytical or finite element results and in all cases the DBEM results were in good agreement with the results from alternative sources.

\section{Р езюме}

Описано застосування методу подвійних граничних елементів для визначення коефіцієнтів інтенсивності напружень у задачах, що пов'язані зі згином пластин. Умови навантаження включають внутрішній тиск та комбінацію згину $з$ розтягом. Коефіцієнти інтенсивності напружень для змішаних мод оцінюються за допомогою методу екстраполяції переміщення поверхні тріщини та методу $J$-інтеграла. Результати розрахунків методом граничних елементів для досліджуваних випадків навантаження порівнюються із даними аналітичних чи скінченноелементних розрахунків. Отримано їх хорошу збіжність.

1. Y. Murakami (Ed.), Stress Intensity Factors. Handbook, Pergamon Press, Oxford (1987).

2. G. C. Sih (Ed.), Mechanics of Fracture, Vol. 3. Plate and Shells with Cracks, Noordhoff, Leyden (1977).

3. M. H. Aliabadi, D. J. Cartwright, D. W. Naehring, and W. H. Davey, "Stress intensity weight factor functions for cracks at holes and half plane," in: C. A. Brebbia and J. J. Connor (Eds.), Proc. of 11th Int. Conf. on Boundary Element Methods, Computational Mechanics Publications, Southampton (1989), Vol. 3, pp. 83-98.

4. B. Stok and B. Bukovec, "Stress intensity factor analysis in cracked elastic bars under torsion by the boundary element method," in: C. A. Brebbia and J. J. Connor (Eds.), Proc. of 11th Int. Conf. on Boundary Element Methods, Computational Mechanics Publications, Southampton (1989), Vol. 3, pp. 111112. 
5. E. Reissner, "On the bending of elastic plates," Quart. Appl. Math., 5, 55-68 (1947).

6. B. J. Karam and J. C. F. Telles, "On boundary elements for Reissner's plate theory," Eng. Anal. Bound. Elements, 5, 21-27 (1985).

7. F. van der Weeen, "Application of the boundary integral equation method to Reissner's plate model," Int. J. Num. Meth. Eng., 18, 1-10 (1982).

8. Y. F. Rashed, M. H. Aliabadi, and C. A. Brebbia, "Hyper singular boundary element formulation for Reissner's plates," Int. J. Solids Struct., 35, 2229 2249 (1998).

9. S. Y. Ahmadi-Brooghani and J. L. Wearing, "The application of the dual boundary element method in linear elastic crack problem in plate bending," in: Proc. of 18th Int. Conf. on Boundary Element Methods, C. A. Brebbia, J. B. Martins, M. H. Aliabadi, and N. Haie (Eds.), Computational Mechanics Publications, Portugal (1996), pp. 429-438.

10. A. Portela, M. H. Aliabadi, and D. P. Rooke, "The dual boundary element method: effective implementation for crack problems," Int. J. Num. Meth. Eng., 33, 1269-1287 (1992).

11. T. Dirgantara, Boundary Element Analysis of Crack in Shear Deformable Plates and Shells, PhD Thesis, Department of Engineering, Queen Mary and Wesfield College, University of London (2000).

12. H. Sosa and G. Herrmann, "On invariant integrals in the analysis of cracked plates," Int. J. Fract., 40, 111-126 (1989).

13. M. H. Aliabadi, "Evaluation of mixed mode stress intensity factors using the path independent $J$-integral," in: Proc. of 12th Int. Conf. on Boundary Elements in Engineering (Hokaido, Japan), Computational Mechanics Publications, Southampton (1990).

14. R. H. Rigby and M. H. Aliabadi, "Mixed mode $J$-integral method for analysis of 3D fracture problems using BEM," Eng. Anal. Bound. Elements, 11, 239-256 (1993).

15. Y. Mi, and M. H. Aliabadi, "Dual boundary element method for three dimensional crack growth analysis," nn: C. A. Brebbia and J. J. Rencis (Eds.), Proc. of 15th Int. Conf. on Boundary Element Methods, Computational Mechanics Publications, Southampton (1993), pp. 249-260. 